\title{
Adverse events of injectables, what kind of jet-skiers should be informed about serious vaginal injury, and what Kant thinks about it
}

\author{
Annette Kuhn
}

Received: 2 May 2008 /Accepted: 2 June 2008 / Published online: 17 June 2008

(C) The International Urogynecological Association 2008

The most important knowledge in the field of patient safety is how to prevent harm to patients during treatment and care. The fundamental role of patient safety reporting systems is to enhance patient's safety by learning from failures of the health-care providers and system. If these failures are not reported-or if serious side effects after medical interventions are not reported-physicians all over the world will repeat the same mistakes.

Therefore, publishing adverse events of a certain treatment is one form of safety reporting system.

From critical incidence reporting systems (CIRS), we know that most problems are not just a series of random, unconnected on-off events, but are provoked by weak systems and often have common root causes, which can be generalized and corrected [1]. Although each event is unique, there are likely to be similarities and patterns in sources of risk that may otherwise go unnoticed if incidents are not reported and analyzed. Ultimately, it is the action we take in response to reporting-not reporting itself-that leads to change.

Only few serious adverse events after the treatment using bulking agents for urinary incontinence are reported; by the way, there is a similar number of medlined papers on serious vaginal trauma in jet-skiers. Does this mean that we can neglect these side effects because there are so few?

Only five papers deal with serious vaginal trauma in jetskiers, but estimating the number of people who do jet ski, there must be a couple of more accidents than those that are

\section{A. Kuhn $(\triangle)$}

Department of Urogynaecology, Frauenklinik, Inselspital,

Effingerstr. 102,

CH-3010 Bern, Switzerland

e-mail: annette.kuhn@insel.ch reported. It might be similar for serious side effects of bulking agents.

We probably dislike reporting complications and negative findings-in sports, because it is meant to be a fun activity, in medicine because we want to offer successful treatments to patients who expect to have their condition improved.

Bulking agents have been approved by the Food and Drug Administration (FDA) for use in women with intrinsic sphincter deficiency and are generally seen as the most minimally invasive surgical intervention with few side effects [2]. Due to its minimal invasiveness, some authors do not even consider this treatment as surgical but as belonging to conservative treatment. From our own experience, we know that the smaller the intervention is, the less preoperative information is usually given to the patient.

Bulking agents have also been used off-label for the treatment of stress urinary incontinence in men, especially after radical retropubic prostatectomy in which incontinence varies from $2.5 \%$ to $87 \%$ [3, 4$]$.

A recent publication reports a $41 \%$ urethral erosion rate in men who were injected with ethylene vinyl alcohol [5]. One patient suffered from extreme dysuria, urgency, and frequency and required multiple follow-up visits and cystoscopic removal of the extruded material. Urethral erosion of permanent injectable material is a scary condition and may result in a drainpipe urethra with concomitant recurrent infections, as well as deteriorating incontinence, which then is difficult to treat. In another study using the same material for the treatment of intrinsic sphincter deficiency in women, the same group reported a $37 \%$ erosion rate in 19 patients, with 4 suffering from extreme pain and dysuria and finally 1 requiring repeat cystoscopy to remove the eroding material [6]. 
If there is a serious accident during jet-skiing including a vaginal laceration even requiring ligation of an iliac artery to save the patient's life [7], the patients will probably tell us "Had I only known before...!"

If patients are worse after treatment, it is painful and sometimes dangerous for the patient, and stressful for the surgeon. This patient might have the same feeling as the unfortunate jet-skier.

Looking at the evidence in Medline and the Cochrane Database [8], the benefit of bulking agents clearly overweighs the risks, but the latter may be underreported.

Periurethral mass formation after transurethral injection has been described for most bulking agents; sterile abscesses have been reported for carbon-coated zirconium-oxide beads, collagen, and-more recently-hyaluronic acid, leading to pain and secondary intervention. The current case in this edition by Fatton et al. describes a prostate-like mass caused by dextranomer microspheres in a cross-linked hyaluronic acid vehicle leading to obstruction, which fortunately resolved after drainage. The mechanism causing these sterile abscesses to occur has not been explained so far; injection technique, the substance itself, and underlying morbidities have been discussed. Periurethral masses, which require drainage, threaten continence, may result in urethral scarring, and must be considered as a serious adverse event.

If voiding dysfunction occurs after bulking agents, the possibility of periurethral mass formation needs to be considered; we can only consider situations we know about, and this is why we should encourage publishing complications and negative study results.

Despite the minimalism of the intervention, the medical community needs to know about these side effects because information will influence product choice, and doctors are obliged to inform the patient.

We act wrongly, Kant claims, when we treat people in any way to which they cannot possibly consent [9]. On the consent principle, it is wrong to treat patients in any way they cannot rationally consent if they know the relevant facts and we give them the power to choose how we treat them. For jet-skiers, the relevant fact is probably that it is a fun activity, which seldom leads to a serious health-threatening accident.

In medicine, this is different. Information about potential serious side effects of treatments must be given to the patient. When surgical procedures or drugs are recommended as off-label use, this status must be declared, and information about unwanted effects should be explained and documented thoroughly.

Injection therapy has been used sparingly for the management of stress urinary incontinence for more than 2 decades, but has been limited by antigenicity issues associated with bovine collagen and durability of continence. Therefore, bulking therapy has been less than optimal to date. For the future, the goal of endoscopic injection therapy is to provide a minimally invasive, safe, cost-effective, and durable alternative to open surgery.

Bulking agents can be used effectively and safely; however, a few serious side effects do occur. Patients need to be informed about this because otherwise they cannot really consent.

In general, jet-skiers do know that they are prone to accidents-only Essex girls need to be informed additionally about serious vaginal trauma.

\section{References}

1. World Alliance for Patients Safety Forward Program 2005; Geneva, World Health Organization 2004

2. Dmochowski RR Appell RA (2000) Injectable agents in the treatment of stress urinary incontinence in women: where are we now? Urology 56:32-40

3. Majoros A Bach D Keszthelyi A (2005) Urinary incontinence and voiding dysfunction after radical retropubic prostatectomy (prospective urodynamic study). Neurourol Urodynam 25:2-7

4. Alivizatos G, Skolarikos A (2005) Incontinence and erectile dysfunction following radical prostatectomy: a review. Sci World J 13:747-758

5. Hurtado EA, McCrery RJ, Appell RA (2008) Complications of ethylene vinyl alcohol as an intraurethral bulking agent in men with stress urinary incontinence. Urology 71(4):662-665

6. Hurtado EA, McCrery RJ, Appell RA (2007) The safety and efficacy of ethylene vinyl alcohol copolymer as an intra-urethral bulking agent in women with intrinsic sphincter deficiency. Int Urogynecol J 18:869-873

7. Haefner AK, Andersen HF, Johnson MP (1991) Vaginal laceration following a jet-ski accident. Obstet Gynecol 78:986-988

8. Keegan P, Atiemo K, Cody J, McClinton S, Pickard R (2007) Periurethral injection therapy for urinary incontinence in women. Cochrane Database systematic Rev 18(3):CD003881

9. Immanuel Kant: The Groundwork, hence worth G 392, page references are to the page numbers of the Prussian Academy 